\title{
Emergence of human resilience in coastal ecosystems under environmental change
}

\author{
Nilufar Matin $^{1}$ and Richard Tavlor ${ }^{2}$
}

\begin{abstract}
Resilience has been studied in a number of disciplines, predominantly in psychosocial and ecological sciences. Although there are striking similarities in their approaches, the psychosocial tradition has centered on the family and its immediate surroundings, whereas the social-ecological approach has focused on macrosystems that stop at the family level. Recently, the need for bridging these gaps has been echoed by researchers from both these traditions, particularly for promoting resilience of individuals and their wider environment in the context of natural disasters and climate change. However, a new synthesis of social-ecological and behavioral theories integrating multiple dynamic systems that interact across levels is strikingly rare. We addressed some of these issues in the context of complex coastal ecosystems in the Sundarbans region in southwest Bangladesh soon after the Cyclone Aila, which hit the coast in May 2009. The devastation that followed tested the endurance and resilience of people and nature alike. We used an integrated method that combined Antonovsky's sense of coherence scale with narrative inquiry for assessing human resilience. The quantitative analysis was able to address gender, educational, and livelihood dimensions of individual resilience. Life history narratives were found particularly useful in bringing out the underlying contexts and processes that embody individual social-ecological interactions that influence the construct of human resilience. These exercises show that the emergence of human resilience must be understood as a holistic and dynamic process because the variables that contribute to its emergence interact in complex ways.
\end{abstract}

Key Words: complexity; human resilience; narrative inquiry; psychosocial; sense of coherence; social-ecological

\section{INTRODUCTION}

Human resilience has predominantly been studied in development psychology, psychiatry, and other behavioral sciences. Early work in this field focused on children who grew up in adverse circumstances yet were able to function properly as adults. The question of what makes a difference in the lives of these children led to a growing interest in protective factors and processes that bring about changes in life trajectories from risk to adaptation. Mechanisms that protect people against the psychological risks associated with adversity were viewed in terms of reduction of risk impacts, establishment and maintenance of self-esteem and self-efficacy, and opening up of opportunities (Rutter 1987, Masten et al. 1990, Garmezy 1991, Werner 1993). In later studies, resilience is understood as the maintenance of positive adaptation by individuals despite experiences of significant adversity (Luthar et al. 2000, Luthar and Brown 2007, Gartland et al. 2011, Masten and Tellegen 2012). The emphasis has over the years shifted from normal recovery to positive transformation (Masten and Obradović 2006, Bonanno 2012, Rutter 2012).

Analysis of psychosocial resilience has recently included aspects of large-scale catastrophic stressors. These events, such as floods and earthquakes, war and displacement, or terrorist attacks, can result in loss, trauma, and other forms of acute adversity that affect a large number of people and communities. Research comprises an impressive array of studies that include exploring psychological distress after the 11 September 2001 terrorist attack in the United States (Sattler 2003, Bonanno et al. 2006); displacement and family resiliency following Hurricane Katrina in 2005 (Glandon et al. 2008, Hackbarth et al. 2012); ethnocultural beliefs after the 2004 Asian tsunami (Rajkumar et al. 2008); and war-induced displacement in Eritrean (Almedom et al. 2007) and North Caucasus communities (Parker et al. 2013). These studies widened the focus of resilience research to explore ways in which individuals and social systems can absorb shocks and adapt to new situations.
Alongside studies on human resilience, an almost parallel development was taking place in research on ecological resilience (Holling 1973, Gunderson 2000). Resilience in ecology is defined as the capacity of a system to absorb disturbance and reorganize while undergoing change so as to still retain essentially the same function, structure, and feedbacks and, therefore, its identity. Most ecosystems have been impacted by human activities; hence, it soon became apparent that ecological resilience needed to be conceptualized in relation to social interventions (Adger 2000). The concept of coupled social-ecological systems (SESs) grew out of this recognition that could incorporate the capacity for renewal, reorganization, and development (Berkes et al. 2003, Folke 2006), which is essential for a sustainability discourse.

The previous description shows that there are striking parallels in resilience theory across the psychosocial and ecological sciences. Despite this, most resilience research within the psychosocial tradition has centered on the family and its immediate surroundings, whereas the social-ecological approach has focused on macrosystems that stop above the family level (Martin-Breen and Anderies 2011). Interestingly, the need for bridging these gaps came from the urgency of promoting resilience of individuals and their wider environment in the context of natural hazards and is echoed by researchers from both these traditions. Masten and Obradović (2008) urge for the integration of research on human resilience with the theory and knowledge gained from disciplines that take a systems approach. Similarly, Gunderson (2010) offers concepts of ecological resilience, e.g., adaptive cycles and panarchy, for managing complex systems with human and ecological components in the face of recurring natural disasters. However, although the need for a new synthesis of developmental, ecological, and family systems theory is beginning to be recognized (Masten 2013), integrating multiple dynamic systems that interact across levels is strikingly rare. 
We seek to contribute to this discussion in the context of complex coastal ecosystems in the Sundarbans in southwest Bangladesh. We explore, first, what the constructs of human resilience are at the individual level and, second, how resilience of individuals is connected to the functioning of the wider SES. We apply concepts of "emergence" and "causation" from complexity thinking to understand connections between individuals' attributes, their psychosocial resilience, and the system-level social-ecological properties. We provide a description of the research context and describe the methodology, followed by data analysis. We also present the emergence of resilience, the interconnectedness of the individual to the SES, and, finally, our conclusions.

\section{THE CONTEXT}

The case study villages are located in Gabura union, which falls within Shyamnagar upazila, i.e., the lowest administrative unit that sits below the district level, in Satkhira district in southwest Bangladesh. In the beginning of the 20th century, this area was characterized by relatively low population, traditional agriculture and artisanal fishing, and ready availability of common pool resources. It was adapted to natural conditions shaped by saline tidal flows and freshwater rivers. Production was generally low, and seasonal floods were common. In the 1960s, engineering works started to protect the coastal areas from open tides and water surge, and extensive embankments and dykes were built. This created the opportunity for shrimp aquaculture in traditional rice fields, now empoldered by dykes. Initially, these fields were used for rice between the months of August and January and for shrimp from February to July. Controlled tidal water exchange was important for trapping wild shrimp larvae and natural food, as well as for maintaining water quality, and the embankments facilitated this (Rahman et al. 2006a).

In the 1980s, world market demand and high prices for shrimp led to new government policies to promote shrimp aquaculture as a source of foreign exchange (Guimarães 1989). Saline water shrimp production became very profitable, giving rise to a group of capitalist investors from outside the area competing for opportunities to expand export production. Smallholders were integrated into the system through leasing or buying of their lands and, often, if land was denied, occupying it with force (Chowdhury 2006). The shrimp farmers were rich, had cash to invest in acquiring land, and were capable of controlling the entire chain from production to export. As the shrimp farmers assumed total control of dykes and sluice gates, saline water was retained in the fields often throughout the year making it unsuitable for paddy cultivation on which smallholders depended. The land gradually lost fertility because of high salinization, reduction of alluvial deposits, and indiscriminate use of chemicals. Large numbers of landless households were forced to migrate to other areas in search of employment. There was an overall loss of common property resources, and ecosystem services were reduced to critical levels (Datta 1993).

On 26 May 2009, Cyclone Aila struck the area. It created major breaches to the embankments and completely inundated the land with saline water, making the entire population homeless and destroying the shrimp and agricultural fields. The area remained underwater for more than a year, technical and financial constraints delaying the reconstruction of the hydraulic structures. Many had to migrate to other areas in search of livelihoods, both temporarily and permanently. The environmental disaster led to complete economic collapse. When we went into the area in September 2009, most people were still living on the road cum embankment that was the only available high ground amid what looked like a sea with the Sundarbans on the horizon.

\section{METHODOLOGY}

In explaining the emergence of human resilience in the complex adaptive system of the coastal Sundarbans, we have drawn on the traditions of complexity thinking. This allowed consideration of individuals in relation to a multitude of heterogeneous actors and factors, interacting and changing in parallel and across many levels (Holland 2006). Complexity science provides a new imagery of such a world, as dynamic, unpredictable, novel, and emergent leading to an understanding that "is holistic, historical, and qualitative, eschewing deductive systems and causal mechanisms and laws" (Kellert 1993:114). We found it particularly apt because it also lends itself to the contextually sensitive narrative mode of thinking (Tsoukas and Hatch 2001). Complexity, as Browning and Boudès (2005) suggest, is best understood with a narrative.

We used both qualitative and quantitative data. We relied on life history narratives to understand resilience from the perspectives of participants, as a sense-making tool for reflection to the narrator, and for holistic insight to the researcher (Czarniawska 2004, Riessman 2007). To complement individual stories, we also constructed group narratives that chartered the social and ecological contexts and trends in the area. This is extremely useful because narratives are essentially context dependent and private stories must mesh with deep structures about the nature of life itself in a particular, historically conditioned culture (Bruner 2004).

For quantitative analysis, we have used the sense of coherence (SOC) framework as formulated by Aaron Antonovsky (1979, 1987). Antonovsky sought to identify how individuals remained physically and mentally healthy despite enduring conditions of severe stress. This led to a theory of coping termed the SOC, which comprises three core components, i.e., comprehensibility, manageability, and meaningfulness. The idea that a strong SOC is essential for successfully coping with life stressors has been adapted to explain health and its dimensions in widely varied situations (Eriksson and Lindström 2006, 2007). Linking Antonovsky's focus of managing stress and staying well to human resilience was first proposed and developed by Almedom et al. (2005, 2007). We adapted Almedom's approach for our study; we used the shorter version of the SOC scale consisting of 13 questions, rather than the longer version with 29 questions. The 13 questions were translated into Bengali and assessed on a 5point Likert scale. As in Almedom's studies, we also felt the need to adapt question 10 to suit the linguistic and emotional context of the research. Thus, the Bengali version adapted the words "sad sacks (losers)" to "losing the battle of life." Details of the SOC questionnaire and its adaptation can be found in Antonovsky (1987) and Almedom et al. (2007). Antonovsky's "generalised resistance resources" (GRR) were of particular importance to us because they "help to make sense out of the countless stressors with which we are constantly bombarded" (Antonovsky 1987:48). We have explored the interplay between individuals' resilience scores and their ability to use GRR as evidenced from life history narratives to construct a holistic and dynamic understanding of human resilience. 
Fig. 1. Comparison of sense of coherence scores among female and male respondents (left), respondents with high and low education (center), and respondents with secure and insecure livelihoods (right).
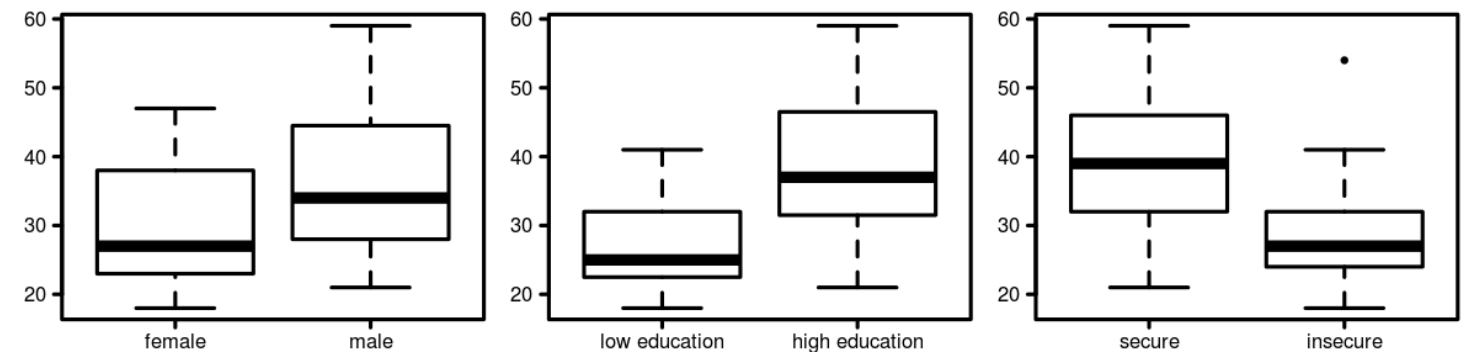

\section{DATA ANALYSIS}

The respondents came from 7 villages that went underwater following the cyclone. During the interviews, many people were still living in temporary shelters on the road cum embankment, whereas some had gone back to their homes. The situation was far from normal because the breached embankment was not yet repaired. The responses are thus reflective of the broader context in which the participants found themselves. The research was done in two phases: first from September to December 2009, when individual and group narratives were recorded; and second, in October to November 2010, when the SOC interviews were conducted. The SOC-13 questionnaire was administered to 43 respondents, among them 19 women and 24 men. The data were analyzed with R Statistical Software (R Development Core Team 2014). Two-sample tests were performed comparing data between two groups for each factor; these were two-tailed t tests (Welch) and analysis of variance tests for difference of means. We analyzed individual resilience scores to discern the effects of 3 personal attributes, i.e., gender, education, and occupation.

Overall, women's resilience was lower compared to men's resilience. Figure 1 (left panel) compares men's and women's SOC scores. The mean score for women was 30.8, whereas for men it was 36; see also Table A1.1 in Appendix 1 for details. However, applying Welch's t test does not show that the difference between means is significant: $\mathrm{t}(40.86)=1.676, \mathrm{p}<0.1014$.

Women who scored low on resilience were mostly single heads of households ( 9 out of 10). Some among them lost their husbands to tiger attacks while they went to collect forest products from the Sundarbans. These women came to be known as tiger widows. Fatima, who scored the lowest (SOC 18), is one of them. She was in chronic stress when the cyclone struck, and she lost everything. Remarkably, 2 female participants having above-average SOC scores were tiger widows and worked as day laborers. One of them, Mamata, showed striking inner optimism (Carver et al. 2010). Her social relations, developed through her role as a leader of a support group for tiger widows, made her the strong and resilient person that she is now despite her traumatic life. Other women who scored higher on resilience came from relatively educated and well-off families. For example, Ayesha (SOC 39) is a local councillor and also owns shrimp farms; Nirmala (SOC 46) owns a mobile telephone business. Male respondents who scored low on resilience seemed to have experienced a sharp worsening of their situations after losing all they had and found it hard to comprehend and manage their stress. Men who scored high on resilience had higher education and secured livelihoods, such as shrimp farms or regular jobs.

Our findings on women's average lower resilience compared to men has also been observed in some other studies, for example, on survivors of the World Trade Center attack of 11 September 2001 (Weissman et al. 2005, Bonanno et al. 2006); on the hospitalized survivors of the severe acute respiratory syndrome epidemic in Hong Kong in 2003 (Bonanno et al. 2008); and on Swedish tourist survivors of the 2004 Southeast Asian tsunami (Johannesson et al. 2011). Little, however, is known about a potential explanation for this (Rodriguez-Llanes et al. 2013), and there is a need for more focused studies on this phenomenon.

Next, we compared participants in relation to their educational levels (Fig. 1, center panel). Education was categorized as low, i.e., no schooling and schooling up to year $5(\mathrm{n}=20)$, and high, i.e., schooling above year 6 up to the master's level $(n=23)$. The high- and low- education groups are compared showing that respondents having higher education scored higher on the SOC scale. Welch's t test shows that the difference between means is significant: $\mathrm{t}(36.47)=-4.6784, \mathrm{p}<3.898 \mathrm{e}-05$. The variance among highly educated respondents is also higher $(\mathrm{F}=0.3512$, $\mathrm{p}<0.02466)$. This finding is similar to impacts of education found in other contexts. Education resulted in better coping and adaptation in El Salvador and Brazil (Wamsler et al. 2012); in reducing both short- and long-term vulnerabilities in Cuba, Haiti, and the Dominican Republic (Pichler and Striessnig 2013); and in better psychosocial health and higher levels of resilience in Sumatra, Indonesia, 5 years after the Asian tsunami (Frankenberg et al. 2013).

Finally, SOC scores were compared between respondents having secure livelihoods $(n=21)$ and insecure livelihoods $(n=22)$ in Figure 1 (right panel). Livelihood security was defined in terms of regularity and adequacy of the sources of income. For example, a job as a teacher; regular employees of nongovernmental organizations, police, and the government; shrimp and poultry farmers; and business were considered secure livelihoods. Conversely, working as day laborers or forest collectors, petty trading, or fishing were considered insecure livelihoods. As could be expected, respondents with more secure occupations have higher scores. Welch's t test shows the difference between means to be significant: $\mathrm{t}(36.725)=3.6846$, $\mathrm{p}<7.342 \mathrm{e}-04$. The impact of better livelihoods on resilience is also noted by Alinovi et al. (2010) in Kenya. 
In summary, two-sample $\mathrm{t}$ tests for gender, educational, and livelihood properties of respondents suggest that people with higher education score significantly higher than those with a lower educational level, and people with secure livelihoods score significantly higher than those with insecure livelihoods. However, there is no significant difference between the SOC scores of men and women.

\section{HUMAN RESILIENCE IN A COMPLEX ADAPTIVE SYSTEM}

To complement the quantitative measure of resilience in Data analysis, we attempt to explain resilience through a lens of complexity concepts, particularly "emergence" and "downward causation" drawing on Sawyer (2002, 2003, 2012), Bruner (1991), Tsoukas and Hatch (2001), Browning and Boudès (2005), and Andersson et al. (2014). These authors have critically used narrative inquiry as a tool for explaining the nuances of emergence in diverse social contexts, as in theater groups or social organizations. We use narrative case studies to explore whether resilience can be explained by properties at the individual level and how it can be connected to the functioning of wider SESs. First, we consider "emergence," i.e., interactions of individual attributes with contextual and situational factors at the microlevel. As we shall see, given the multitude of factors acting in parallel, one cannot readily identify a universal mechanism for emergence of resilience; moreover, human resilience may only be partially explained in terms of the factors investigated. Second, we explore "downward causation," i.e., how resilience, once it has emerged as a higher level property of the SES, enables and constrains what actors are able to do at individual levels. Although the following discussion is underpinned by complexity concepts, no attempt is made at theorizing them given the limited scope of this research. However, we hope to contribute to exploring the mechanisms of emergence that, as Sawyer (2004:267) suggests, have "the potential to unify micro and macro sociological perspectives."

\section{Emergence of resilience}

In describing emergence of resilience, we have looked into, first, attributes of individuals, such as gender, education, and occupation, as well as personal histories of trauma compounded by the cyclonic disaster; and, second, social and contextual properties, such as roles of institutions, ecosystem services, social support, or gender norms. The narratives are used to make sense of the statistical correlations of individuals' attributes with their resilience scores, some of which seemed counterintuitive.

First, we examine Kanchan and Sajid, who, despite having similar resilience scores (SOC 32 and 34, respectively), have had very different life experiences. Kanchan is in her midthirties, a tiger widow with 4 children and with little education and wealth. She lost her husband 9 years ago and since then has been the sole earner for the family:

After my husband's sudden death, I had to start working as a day labourer; sometimes I would also collect shrimplarvae from the river to feed my family. During the cyclone, our house completely went under water, we couldn't save anything. A neighbour helped us to get onto the road in their boat. When the water receded, we found that the land where our house once stood has eroded so much that it has become a water pond. I received some relief material, such as bamboos, Nypa leaves [Nypa fruticans ], and polythene sheets, and managed to build a shed on a platform on the water. Inow work as a labourer in the 'food for work' programme, and thus we survive. I cannot sleep at night, thinking about what will happen to us, to my children.

Sajid, on the other hand, has a very different background. He is also in his thirties, has studied up to year 9, and comes from a well-off family. His father is a retired teacher, and the family owns shrimp farms. During and after the cyclone, they were able to stay on in their home, unlike many others. Although the house went 2 feet underwater, they managed to erect bamboo platforms to keep themselves and other essentials above the water. Sajid describes his experience after the cyclone as follows: "Since then I have worked as a labour manager in road construction for about 6 months. We got a relief card for $20 \mathrm{~kg}$ rice per month for 16 months. Most of our shrimp land is now outside the new ring bund, and as such completely submerged. I don't think this land will ever accrete for any use."

The trauma and suffering Kanchan has endured and the strength she has displayed in running her family cannot be assessed only from her resilience score. Following Bandura (1977), we may explain it as "experiences of mastery" resulting in enhanced selfefficacy in the context of chronic stress. On the other hand, Sajid's postcyclone experience resulted in lower self-efficacy in the context of resource loss that was sudden and drastic. The previous stories suggest that individual attributes and temporal and contextual factors interact diversely and could lead to the emergence of resilience in very different ways. The same levels of resilience may emerge from very different individual attributes through very different mechanisms.

Further, we compare the cases of Ashok and Amin. They seem to have similar personal attributes in terms of gender, age, and education, as well as similar livelihoods; however, they have very different resilience scores. Ashok's resilience score is 34, whereas Amin's score is the lowest male score (21). Ashok narrates his experience:

When the water rushed in, we left the house and took a boat to get to a safe place. It was high wind and high tide, and the boat capsized. I tried my best to save my wife and children. But I could not hold on for long. My wife, daughter, and the youngest son died in my arms. Then we saw a floating thatch roof and holding on to it we somehow managed to reach the shore. Since then we are living on relief and any wage work that we can get. I had a secure crab and fish business before the cyclone, this is gone now.

On the other hand, Amin sums up his situation as follows:

I had a good business in dry shrimp and fish; I also had a poultry farm. Aila swept away my home and business. Since then we are living on relief and on wage work as and when available. Neither I nor my wife has worked as menial labourers before, but we have to do this now for survival. I cannot start the business as I lost all my capital. I had some outstanding loans and the lender is asking it back, phoning repeatedly. I cannot face to see him, I feel such a shame. My elderly parents are suffering too, and I don't have means to help them. 
The previous stories point out the traumatic experiences that these men have gone through. It is understandable for Amin to feel low and hopeless because he sees himself in unforeseen misery. It is significant that he talks about his "shame," which is recognized as a nonmaterial and social dimension of poverty (Jo 2013). For him, the shame of his impoverished condition was a big blow to his sense of ego and was reflected in his low resilience score. Ashok, on the other hand, had gone through what is undeniably a major personal trauma. Despite this, his resilience score was much higher. Given the limited scope of our study, it was not possible to adequately assess his "personal agency," which is often cited as a strong characteristic of resilience (Rutter 2006). However, as his detailed narrative suggests, it seems possible to explain this in terms of his inherent optimism (Scheier and Carver 1985, Benight and Bandura 2004), which is considered a predictor of perceived capability to manage the demands of a potentially traumatic event. Resilience may also be affected by "historicity" of the individual's experience, e.g., his or her temporal and historical circumstances. Ashok's and Amin's cases suggest that similar individual attributes may follow very different mechanisms and may lead to very different levels of resilience.

\section{Downward causation}

We describe how resilience at a higher level as a social property might impact on individual lives and livelihoods. Downward causation of social properties is particularly contentious, and although researchers are increasingly providing empirical evidence from narrative inquiry, the debate is still rife on a theoretical level; discussions between Greve (2012) and Sawyer (2012) can be cited as an example. We are aware that our limited research cannot claim to empirically identify mechanisms of downward causation; nevertheless, we hope to throw some light on how resilience at a higher level, i.e., at the level of the SES, influences the actions and interactions at the lower, i.e., individual, levels.

In The context, we described how the natural ecological features of this coastal area prompted construction of embankments and brought the control of water to rich shrimp farmers who steadily transformed the erstwhile agricultural land into shrimp fields for the export market. This created conditions for profit and power to become mutually reinforcing where highly connected individuals control the system by ignoring the social costs, i.e., loss of livelihoods for the majority, as well as the environmental costs, i.e., loss of biodiversity and land degradation, using their social and political influence. Transformations in land use resulted in a reduction of diversity of ecosystem services in the area and increasing concentration of the benefits in the hands of an increasingly smaller group of stakeholders (Adams et al. 2013). As a result, Matin et al. (2014) note that the SES in this area has gradually evolved into a "rigidity trap." This is a situation in which weak institutions become self-reinforcing and inflexible (Carpenter and Brock 2008) and fail to address the emergence of new risks at a higher level of aggregation, i.e., environmental degradation and social conflict.

The influence of SES resilience on individual levels can be seen from life stories in which the narrators connect the micro to the macro. The Sundarbans, although a reserve forest, still provide sustenance to many people. A typical seasonal calendar of activities shows the importance of natural ecosystems in people's livelihoods: honey collection from March to April, fishing from
May to September, crab hunting from September to October, and woodcutting and collection of Nypa palm leaves from November to December. Fish fry collection and fishing in the rivers are done throughout the year; the peak season for fish larvae collection is January to February. Since the spread of shrimp cultivation, local employment possibilities have been drastically reduced because shrimp farming does not require much labor compared to agriculture. Policies thus had the effect, if unintended, of pushing people more toward using the forests and rivers for survival. This in turn resulted in reduction of biodiversity, as we heard in the group narratives: "The rivers now do not have the variety and amount of fish that we used to catch earlier, the river water is too saline and too polluted, and too many of us are fishing. The valuable trees in the Sundarbans are all gone, you don't see much Sundari [Heritiera fomes]; the mangrove isn't as dense as it used to be." Thus, people are compelled to go deeper inside the mangroves in search of resources despite the risk of being attacked by tigers and certain death.

We also heard from women's group narratives about how years of shrimp aquaculture had increased salinity to such a level that women's livelihoods were nearly lost:

We cannot do anything else here-we lost our livestock
as there is no grazing land left, so children don't have
milk, the income from milk is also lost. Earlier, we used
to keep chicken and ducks, but as most of the area is
under water, they are not allowed to freely range anymore.
We cannot grow vegetables, the land is too saline. Also
the fruit trees are not bearing any fruit, many have died.
There is hardly any crop processing work, as hardly any
crops grow. We can get employment only in collecting
shrimp larvae standing in the river water, often in the dark
of nights.

Livelihoods in these villages were already vulnerable, and Cyclone Aila compounded this, resulting in overall low resilience for many people, and more so for women.

The loss of social-ecological resilience, however, was realized in individual lives in different ways. Nikhil is an enterprising man, aged 40 , who moved to the city after the cyclone. We spoke to him when he came back to the village to see relatives. He told us: "When I was 3 years old, my father was killed in a tiger attack. So I started fishing with my mother at an early age. Soon I also started going to fishing in the Sundarbans as there was hardly any other work in the area. People like me who do not have many options, die from tiger attacks." Nikhil lost everything in Cyclone Aila and was trying to make a living as a rickshaw worker. On the other hand, we also heard from Balai, a shrimp farmer, about how he managed the post-Aila devastation:

Since 1998 I am cultivating shrimp and made good profit for a few years. At that time, my relatives from the city advised me to buy land there. As we lived in such a hazardous environment with cyclones, tidal surges, salinity, I also thought it would be better to move to the city. So after Aila, we built a house there, and started a poultry farm; with this income I should be able to maintain my family and children's education. I don't want to come back to the village to live, though I would continue to cultivate the shrimp farms.

People who can show such resilience, however, are few in number. 
Other studies in the Sundarbans have also shown that livelihood resilience is linked to overall loss of biodiversity, land degradation, and the cascading vulnerabilities in the SES (Rahman et al. 2006b). If, as suggested, downward causation of the SES properties, such as rigidity of institutions and degradation of ecosystems, coevolved with increasingly less diverse land and water use, and if this left the majority of individuals less able to depend on local ecosystem services and forced them into risky and unsustainable livelihoods, then it would be an example of system-level resilience impacting at individual levels, adversely for the majority and favorably for the few.

\section{CONCLUSIONS}

The devastation caused by Cyclone Aila severely affected the people and the ecosystems, thereby disrupting the linkages between them. The result, as we described previously, was near complete erosion of ecosystem services and severe distress and hardship for people. The cyclone tested the endurance and resilience of people and nature alike.

Using the SOC scale together with life history narratives provides a mixed quantitative and qualitative analysis of human resilience to natural hazards. We have applied this across seven flooded villages in the affected area. The quantitative analysis was able to address gender, education, and livelihood dimensions of individual resilience. The results suggest that people with higher education have significantly higher resilience scores than those with a lower educational level; people with secure livelihoods score significantly higher than those with insecure livelihoods; and men's scores in general were higher than women's scores. Statistical tests on the survey data show differences in education and livelihoods to be significant. Interestingly, gender differences were not statistically significant. Although these properties did not interact in a statistical sense, in-depth qualitative research revealed many other contributing factors interacting with them. We used the ideas of GRR and drew on the concepts of optimism and self-efficacy to bring out the underlying contexts and processes that lead to the emergence of human resilience.

The previous exercise suggests that human resilience could be usefully explained using the theoretical underpinnings of complexity science. Complexity concepts were helpful in capturing factors that were interactive and manifested in multiple outcomes, particularly when personal-contextual-situational factors coevolved in unpredictable ways. We hope to have contributed to a meaningful, if limited, understanding of processes of emergence and downward causation of resilience, and toward a potential integration of micro- and macroperspectives. More research is needed to uncover pathways for escaping the rigidity trap and progressing toward a sociotechnical transition in the Sundarbans. An interdisciplinary approach combining insights from complexity science and participatory inquiry could certainly help.

Responses to this article can be read online at: http://www.ecologyandsociety.org/issues/responses. php/7321

\section{Acknowledgments:}

The work was made possible through financial support provided by the Swedish International Development Cooperation Agency for the project Transformations in Risk. The authors would like to thank Sukaina Bharwani, Tom Downing, Mo Hamza, and John Forrester of Stockholm Environment Institute for constructive feedback. We thank the subject editor and the anonymous reviewers for their useful comments. We are grateful to the people of Gabura and to Shushilan, a nongovernmental organization working in this area, for their help in making this study possible. Particular thanks are due to Rabi Guha for valuable input.

\section{LITERATURE CITED}

Adams, H., W. N. Adger, H. Huq, R. Rahman, and M. Salehin. 2013. Transformations in land use in the southwest coastal zone of Bangladesh: resilience and reversibility under environmental change. Pages 160-168 in Proceedings of Transformations in a Changing Climate (Oslo, Norway, 19-21 June 2013). University of Oslo, Oslo, Norway.

Adger, W. N. 2000. Social and ecological resilience: are they related? Progress in Human Geography 24:347-364. http://dx. doi. org/10.1191/030913200701540465

Alinovi, L., M. D’Errico, E. Mane, and D. Romano. 2010. Livelihoods strategies and household resilience to food insecurity: an empirical analysis to Kenya. European Report on Development, European Union, Brussels, Belgium. [online] URL: http://erd.eui.eu/media/BackgroundPapers/Alinovi-RomanoD\%27Errico-Mane.pdf

Almedom, A. M., B. Tesfamichael, Z. S. Mohammed, C. G. N. Mascie-Taylor, and Z. Alemu. 2007. Use of "sense of coherence (SOC)" scale to measure resilience in Eritrea: interrogating both the data and the scale. Journal of Biosocial Science 39:91-107.

Almedom, A. M., B. Tesfamichael, Z. S. Mohammed, J. Muller, N. Mascie-Taylor, and Z. Alemu. 2005. "Hope" makes sense in Eritrean Sense of Coherence, but "loser" does not. Journal of Loss and Trauma 10:433-451. http://dx.doi.org/10.1080/15325020500193887

Andersson, C., A. Törnberg, and P. Törnberg. 2014. Societal systems - complex or worse? Futures 63:145-157. http://dx.doi. org/10.1016/j.futures.2014.07.003

Antonovsky, A. 1979. Health, stress, and coping. Jossey-Bass, San Francisco, California, USA.

Antonovsky, A. 1987. Unraveling the mystery of health: how people manage stress and stay well. Jossey-Bass, San Francisco, California, USA.

Bandura, A. 1977 Self-efficacy: toward a unifying theory of behavioral change. Psychological Review 84(2):191-215.

Benight, C. C., and A. Bandura. 2004. Social cognitive theory of posttraumatic recovery: the role of perceived self-efficacy. Behaviour Research and Therapy 42:1129-1148. http://dx.doi. org/10.1016/j.brat.2003.08.008

Berkes, F., J. Colding, and C. Folke. 2003. Navigating socialecological systems: building resilience for complexity and change. Cambridge University Press, Cambridge, UK. http://dx.doi. org/10.1017/cbo9780511541957 
Bonanno, G. A. 2012. Uses and abuses of the resilience construct: loss, trauma, and health-related adversities. Social Science \& Medicine 74:753-756. http://dx.doi.org/10.1016/j.socscimed.2011.11.022

Bonanno, G. A., S. Galea, A. Bucciarelli, and D. Vlahov. 2006. Psychological resilience after disaster: New York City in the aftermath of the September 11th terrorist attack. Psychological Science 17:181-186. http://dx.doi.org/10.1111/j.1467-9280.2006.01682. $\underline{\mathrm{X}}$

Bonanno, G. A., S. M. Y. Ho, J. C. K. Chan, R. S. Y. Kwong, C. K. Y. Cheung, C. P. Y. Wong, and V. C. W. Wong. 2008. Psychological resilience and dysfunction among hospitalized survivors of the SARS epidemic in Hong Kong: a latent class approach. Health Psychology 27:659-667. http://dx.doi. org/10.1037/0278-6133.27.5.659

Browning, L., and T. Boudès. 2005. The use of narrative to understand and respond to complexity: a comparative analysis of the Cynefin and Weickian models. E: CO 7:32-39.

Bruner, J. 1991. The narrative construction of reality. Critical Inquiry 18:1-21. http://dx.doi.org/10.1086/448619

Bruner, J. 2004. Life as narrative. Social Research 71(3):691-710.

Carpenter, S. R., and W. A. Brock. 2008. Adaptive capacity and traps. Ecology and Society 13(2): 40. [online] URL: http://www. ecologyandsociety.org/vol13/iss2/art40/

Carver, C. S., M. F. Scheier, and S. C. Segerstrom. 2010. Optimism. Clinical Psychology Review 30:879-889. http://dx.doi.org/10.1016/ j.cpr.2010.01.006

Chowdhury, Z. H. 2006. Network and political analysis of shrimp farming in Bangladesh. Pages 399-416 in A. A. Rahman, A. H. G. Quddus, B. Pokrant, Md. L. Ali, editors. Shrimp farming and industry: sustainability, trade and livelihoods. Bangladesh Centre for Advanced Studies and University Press, Dhaka, Bangladesh.

Czarniawska, B. 2004. Narratives in social science research. Sage, Thousand Oaks, California, USA.

Datta, A. K. 1993. Socio-economic and environmental dimension of shrimp and prawn culture in Bangladesh. Journal of Rural Development 23(2):1-16.

Eriksson, M., and B. Lindström. 2006. Antonovsky's sense of coherence scale and the relation with health: a systematic review. Journal of Epidemiology \& Community Health 60:376-381. http:// $\underline{\text { dx.doi.org/10.1136/jech.2005.041616 }}$

Eriksson, M., and B. Lindström. 2007. Antonovsky's sense of coherence scale and its relation with quality of life: a systematic review. Journal of Epidemiology \& Community Health 61:938-944. http://dx.doi.org/10.1136/jech.2006.056028

Folke, C. 2006. Resilience: the emergence of a perspective for social-ecological systems analyses. Global Environmental Change 16:253-267. http://dx.doi.org/10.1016/j.gloenvcha.2006.04.002

Frankenberg, E., B. Sikoki, C. Sumantri, W. Suriastini, and D. Thomas. 2013. Education, vulnerability, and resilience after a natural disaster. Ecology and Society 18(2): 16. http://dx.doi. org/10.5751/es-05377-180216

Garmezy, N. 1991. Resiliency and vulnerability to adverse developmental outcomes associated with poverty. American
Behavioral Scientist 34:416-430. http://dx.doi.org/10.1177/0002$\underline{764291034004003}$

Gartland, D., L. Bond, C. A. Olsson, S. Buzwell, and S. M. Sawyer. 2011. Development of a multi-dimensional measure of resilience in adolescents: the Adolescent Resilience Questionnaire. BMC Medical Research Methodology 11:134. http://dx.doi. org/10.1186/1471-2288-11-134

Glandon, D. M., J. Muller, and A. M. Almedom. 2008. Resilience in post-Katrina New Orleans, Louisiana: a preliminary study. African Health Sciences 8:S21-S27.

Greve, J. 2012. Emergence in sociology: a critique of nonreductive individualism. Philosophy of the Social Sciences 42:188-223. http://dx.doi.org/10.1177/0048393110381770

Guimarães, J. P. de C. 1989. Shrimp culture and market incorporation: a study of shrimp culture in paddy fields in southwest Bangladesh. Development and Change 20:653-682. http://dx.doi.org/10.1111/j.1467-7660.1989.tb00361.x

Gunderson, L. H. 2000. Ecological resilience-in theory and application. Annual Review of Ecology and Systematics 31:425-439. http://dx.doi.org/10.1146/annurev.ecolsys.31.1.425

Gunderson, L. 2010. Ecological and human community resilience in response to natural disasters. Ecology and Society 15(2): 18. [online] URL: http://www.ecologyandsociety.org/vol15/iss2/ art18/

Hackbarth, M., T. Pavkov, J. Wetchler, and M. Flannery. 2012. Natural disasters: an assessment of family resiliency following Hurricane Katrina. Journal of Marital and Family Therapy 38:340-351. http://dx.doi.org/10.1111/j.1752-0606.2011.00227.x

Holland, J. H. 2006. Studying complex adaptive systems. Journal of Systems Science and Complexity 19:1-8. http://dx.doi. org/10.1007/s11424-006-0001-z

Holling, C. S. 1973. Resilience and stability of ecological systems. Annual Review of Ecology and Systematics 4:1-23. http://dx.doi. org/10.1146/annurev.es.04.110173.000245

Jo, Y. N. 2013. Psycho-social dimensions of poverty: when poverty becomes shameful. Critical Social Policy 33:514-531. http://dx. doi.org/10.1177/0261018313479008

Johannesson, K. B., T. Lundin, T. Fröjd, C. M. Hultman, and P.O. Michel. 2011. Tsunami-exposed tourist survivors: signs of recovery in a 3-year perspective. Journal of Nervous and Mental Disease 199:162-169. http://dx.doi.org/10.1097/NMD.0b013e31820c73d1

Kellert, S. H. 1993. In the wake of chaos: unpredictable order in dynamical systems. Science and Its Conceptual Foundations Series. University of Chicago Press, Chicago, Illinois, USA.

Luthar, S. S., and P. J. Brown. 2007. Maximizing resilience through diverse levels of inquiry: prevailing paradigms, possibilities, and priorities for the future. Development and Psychopathology 19:931-955. http://dx.doi.org/10.1017/S0954579407000454

Luthar, S. S., D. Cicchetti, and B. Becker. 2000. The construct of resilience: a critical evaluation and guidelines for future work. Child Development 71:543-562. http://dx.doi.org/10.1111/1467-8624.00164

Martin-Breen, P., and J. M. Anderies. 2011. Resilience: a literature review. Institute of Development Studies, Brighton, UK. 
Masten, A. S. 2013. Competence, risk, and resilience in military families: conceptual commentary. Clinical Child and Family Psychology Review 16:278-281. http://dx.doi.org/10.1007/ s10567-013-0150-2

Masten, A. S., K. M. Best, and N. Garmezy. 1990. Resilience and development: contributions from the study of children who overcome adversity. Development and Psychopathology 2:425-444. http://dx.doi.org/10.1017/S0954579400005812

Masten, A. S., and J. Obradović. 2006. Competence and resilience in development. Annals of the New York Academy of Sciences 1094:13-27. http://dx.doi.org/10.1196/annals.1376.003

Masten, A. S., and J. Obradović. 2008. Disaster preparation and recovery: lessons from research on resilience in human development. Ecology and Society 13(1): 9. [online] URL: http:// www.ecologyandsociety.org/vol13/iss1/art9/

Masten, A. S., and A. Tellegen. 2012. Resilience in developmental psychopathology: contributions of the Project Competence Longitudinal Study. Development and Psychopathology 24:345-361. http://dx.doi.org/10.1017/S095457941200003X

Matin, N., R. Taylor, and S. Bharwani. 2014. Is equality good for resilience? Exploring human and institutional processes in adaptive cycle heuristic. Page 16 in Stockholm Environment Institute (SEI) Science Forum 2014: Abstracts (Stockholm, Sweden, 27-28 January 2014). SEI, Stockholm, Sweden. [online] URL: http://www.sei-international.org/mediamanager/documents/ Events/ScienceForum2014/SEI-Abstracts-ScienceForum2014.pdf

Parker, J., L. J. Tiberi, J. Akhilgova, F. Toirov, and A. M. Almedom. 2013. "Hope is the engine of life"; "hope dies with the person": analysis of meaning making in FAO-supported North Caucasus communities using the "Sense and Sensibilities of Coherence" (SSOC) methodology. Journal of Loss and Trauma 18:140-151. http://dx.doi.org/10.1080/15325024.2012.684578

Pichler, A., and E. Striessnig. 2013. Differential vulnerability to hurricanes in Cuba, Haiti, and the Dominican Republic: the contribution of education. Ecology and Society 18(3): 31. http:// dx.doi.org/10.5751/es-05774-180331

Rahman, A. A., Md. L. Ali, and D. L. Mallick. 2006a. An overview and perspectives of the Bangladesh shrimp industry. Pages 207-234 in A. A. Rahman, A. H. G. Quddus, B. Pokrant, and Md. L. Ali, editors. Shrimp farming and industry: sustainability, trade and livelihoods. Bangladesh Centre for Advanced Studies and University Press, Dhaka, Bangladesh.

Rahman, A. A., A. H. G. Quddus, B. Pokrant, and Md. L. Ali, editors. 2006b. Shrimp farming and industry: sustainability, trade and livelihoods. Bangladesh Centre for Advanced Studies and University Press, Dhaka, Bangladesh.

Rajkumar, A. P., T. S. Premkumar, and P. Tharyan. 2008. Coping with the Asian tsunami: perspectives from Tamil Nadu, India on the determinants of resilience in the face of adversity. Social Science \& Medicine 67:844-853. http://dx.doi.org/10.1016/j. socscimed.2008.05.014

R Development Core Team. 2014. R: a language and environment for statistical computing. R Foundation for Statistical Computing, Vienna, Austria.

Riessman, C. K. 2007. Narrative methods for the social sciences. Sage, London, UK.
Rodriguez-Llanes, J. M., F. Vos, and D. Guha-Sapir. 2013. Measuring psychological resilience to disasters: are evidencebased indicators an achievable goal? Environmental Health 12:115. http://dx.doi.org/10.1186/1476-069X-12-115

Rutter, M. 1987. Psychosocial resilience and protective mechanisms. American Journal of Orthopsychiatry 57:316-331. http://dx.doi.org/10.1111/j.1939-0025.1987.tb03541.x

Rutter, M. 2006. Implications of resilience concepts for scientific understanding. Annals of the New York Academy of Sciences 1094:1-12. http://dx.doi.org/10.1196/annals.1376.002

Rutter, M. 2012. Resilience as a dynamic concept. Development and Psychopathology 24:335-344. http://dx.doi.org/10.1017/ $\underline{\mathrm{S} 0954579412000028}$

Sattler, D. N. 2003. Resiliency, posttraumatic growth, and psychological distress after the attacks on America. Pages 315-332 in Beyond September 11th: an account of post-disaster research. Institute of Behavioral Science, Natural Hazards Research and Applications Information Center, University of Colorado, Boulder, Colorado.

Sawyer, R. K. 2002. Nonreductive individualism: part Isupervenience and wild disjunction. Philosophy of the Social Sciences 32:537-559. http://dx.doi.org/10.1177/004839302237836

Sawyer, R. K. 2003. Nonreductive individualism: part II-social causation. Philosophy of the Social Sciences 33:203-224. http:// dx.doi.org/10.1177/0048393103033002003

Sawyer, R. K. 2004. The mechanisms of emergence. Philosophy of the Social Sciences 34:260-282. http://dx.doi.org/10.1177/004$\underline{8393103262553}$

Sawyer, R. K. 2012. Response to "emergence in sociology." Philosophy of the Social Sciences 42:270-275. http://dx.doi. org/10.1177/0048393111399239

Scheier, M. F., and C. S. Carver. 1985. Optimism, coping, and health: assessment and implications of generalized outcome expectancies. Health Psychology 4:219-247. http://dx.doi. org/10.1037/0278-6133.4.3.219

Tsoukas, H., and M. J. Hatch. 2001. Complex thinking, complex practice: the case for a narrative approach to organizational complexity. Human Relations 54:979-1013. http://dx.doi. org/10.1177/0018726701548001

Wamsler, C., E. Brink, and O. Rantala. 2012. Climate change, adaptation, and formal education: the role of schooling for increasing societies' adaptive capacities in El Salvador and Brazil. Ecology and Society 17(2): 2. http://dx.doi.org/10.5751/ es-04645-170202

Weissman, M. M., Y. Neria, A. Das, A. Feder, C. Blanco, R. Lantigua, S. Shea, R. Gross, M. J. Gameroff, D. Pilowsky, and M. Olfson. 2005. Gender differences in posttraumatic stress disorder among primary care patients after the World Trade Center attack of September 11, 2001. Gender Medicine 2:76-87. http://dx.doi.org/10.1016/S1550-8579(05)80014-2

Werner, E. E. 1993. Risk, resilience, and recovery: perspectives from the Kauai Longitudinal Study. Development and Psychopathology 5:503-515. http://dx.doi.org/10.1017/S095457940000612X 


\section{Appendix 1.}

Table A1.1. Descriptive SOC statistics for three groups of respondents based on gender, education and livelihoods

\begin{tabular}{lrrrrrrrrrrr}
\hline \hline & $\mathrm{n}$ & mean & std.dev & min & Q1 & median & Q3 & max & ss1 & ss2 & ss3 \\
\hline Female & 19 & 30.8 & 9.3 & 18 & 23.0 & 27.0 & 38.0 & 47 & 7.8 & 14.4 & 8.6 \\
Male & 24 & 36.0 & 11.1 & 21 & 28.0 & 34.0 & 44.5 & 59 & 9.7 & 15.6 & 10.7 \\
Low education & 20 & 27.2 & 6.2 & 18 & 22.5 & 25.0 & 32.0 & 41 & 6.8 & 13.4 & 7.0 \\
High education & 23 & 39.3 & 10.4 & 21 & 31.5 & 37.0 & 46.5 & 59 & 10.6 & 16.5 & 12.2 \\
Secure livelihood & 21 & 39.0 & 10.6 & 21 & 32.0 & 39.0 & 46.0 & 59 & 10.6 & 16.7 & 11.7 \\
Insecure livelihood & 22 & 28.6 & 7.8 & 18 & 24.0 & 27.0 & 32.0 & 41 & 7.1 & 13.5 & 8.0 \\
\hline
\end{tabular}

The first two rows give statistics for female and male, with lower SOC scores on average for females. The second pair of rows show that average scores for highly educated respondents (mean 39.3) are much higher than for low -educated respondents (mean 27.2) whilst the variance is also much higher. The third pair of rows also show a large difference between the higher scores for respondents with a secure occupation and lower scores for those in the insecure category. The columns 1-8 of Table A1.1 summarise data plotted in the three boxplots (Fig.1). The final three columns show the mean sub-scale scores for the three components (where ss1=Comprehensibility, ss2 $=$ Meaningfulness, and ss3=Manageability) across the groupings. 